\title{
Splitting the Pie: Rent Distribution in Alliances and Networks
}

\author{
Jeffrey H. Dyer ${ }^{\mathrm{a}, *}$, Harbir Singh ${ }^{\mathrm{b}}$ and Prashant Kale \\ ${ }^{a}$ Brigham Young University, Provo, UT, USA \\ ${ }^{\mathrm{b}}$ University of Pennsylvania, Philadelphia, PA, USA \\ ${ }^{\mathrm{c}}$ University of Michigan, Ann Arbor, MI, USA
}

\begin{abstract}
This paper addresses the issue of how relational rents, generated through alliances, are distributed to the participating firms. We argue that rent distribution is influenced by factors affecting both jointly generated common benefits and private benefits gained from the alliance relationship. We draw on four perspectives to explain these various effects. The first three, namely the resource dependence perspective, related resources perspective, and structural holes perspective, essentially highlight the private 'exploitation' opportunities that a firm's alliance network presents the focal firm. In contrast, the resource development perspective underscores the private 'exploration' benefits a firm potentially derives from its alliance network. Copyright (C) 2008 John Wiley \& Sons, Ltd.
\end{abstract}

\section{INTRODUCTION}

During the past two decades we have witnessed an extraordinary increase in the number of alliances (non-market relationships) between firms. Indeed, alliances, which are supported by neoclassical or relational contracts rather than the classical contracts that support market relationships (Williamson, 1985), have become one of the most important organizational forms in both the United States and other market economies. More than 10,000 alliances were reported by US firms in 2000 and alliances grew at a 19\% annual rate from 1996 to 2000 (Anand and Khanna, 2000; Forbes, 2001). With the growth in alliances and strategic networks, Dyer and Singh (1998) as well as Gulati et al. (2000) have made the case that dyads and networks of firms are an increasingly important

\footnotetext{
*Correspondence to: Marriott School, Brigham Young University, 790 Tanner Building, Provo, UT 84602, USA. E-mail: jdyer@byu.edu
}

unit of analysis for explaining supernormal profits and the competitive advantage of firms. The idea that alliances generate relational rents ${ }^{1}$ and are an important vehicle for value creation is supported by numerous studies which suggest that, on average, alliances do create economic value (McConnell and Nantel, 1985; Koh and Venkatraman, 1991; Anand and Khanna, 2000; Kale et al., 2002).

But while there is increasing evidence that alliances are an important source of value creation and competitive advantage, we know less about how collaborating firms split the value (rents) that are generated as a result of the collaboration. Why are some firms able to generate greater total benefits from participating in alliances and networks? Why do some firms appropriate more of the rents? Previous research on alliances has focused largely on the reasons for alliance formation, the characteristics of alliance success or failure, and the sources of competitive advantage that can be derived through alliances. But less 
attention has been paid to how total 'relational rents' are generated and distributed among alliance partners.

In this paper we address the issue of how relational rents generated through alliances are distributed to the participating firms. We develop an overarching framework which divides the total benefits that a firm can generate from an alliance relationship into 'common benefits,' or benefits to both parties based upon the alliance's specific objectives as well as 'private benefits' or gain's that are realized only by individual firms in the alliance (Khanna et al., 1998). We then suggest that core arguments of resource dependence theory help best explain how the common benefits are split among parties based upon the nature of the resource dependence between them. On the other hand, the total private benefits that a firm can generate from an alliance relationship can only be understood by using a combination of theoretical perspectives which we label: related resources perspective, structural holes perspective, and resource development perspective. We develop the theoretical arguments from each perspective and use specific case studies to illustrate how relational rents are generated and appropriated in alliance relationships. We also illustrate the interdependent nature of a firm's ability to generate and balance common and private benefits and discuss the implications of our analysis for alliance formation and stability. Finally, we discuss the policy implications for alliance managers and executives.

\section{THEORETICAL FRAMEWORK: THE GENERATION AND DIVISION OF RELATIONAL RENTS FROM AN ALLIANCE}

At first glance, the distribution of rents in an alliance relationship appears straightforward. Each firm brings some resources to the table which, when combined, are able to synergistically generate more value than would be possible if the resources were kept separate. The two parties estimate the size of the pie to be created and then negotiate a split of that pie. According to the resource dependence perspective, we would expect that the partners who bring the more critical (i.e., scarce) resources to the relationship will be able to appropriate a higher percentage of the rents (Pfeffer and Salancik, 1978). However, this perspective alone explains the distribution of relational rents only if neither of the two firms generates any private benefits from the alliance relationship. In many cases firms enter an alliance relationship to achieve goals that are not specifically related to the stated objectives of the alliance. Thus, with regard to the distribution of common (direct) benefits of the alliance relationship, the resource dependence perspective is critical for explaining the distribution of rents. However, it is important to distinguish between common and private benefits. In some cases, firms may enter an alliance relationship to generate private benefits that may not be apparent to the alliance partner, and therefore are not considered in the negotiations that split the common benefits from the alliance. Consequently, it is important to understand that while resource dependence theory may be adequate to describe the ex ante distribution of common benefits, it is inadequate in its ability to explain how and why some firms generate greater private benefits from an alliance relationship. The private benefits that result from an alliance can be explained through three other theoretical approaches:

1. Related resources perspective. The ability of the firm to exploit knowledge/resources acquired through the alliance by combining them with related/complementary resources within the firm.

2. Structural holes perspective (Burt, 1992). The ability of the firm to exploit knowledge/ resources acquired through the alliance by combining them with the resources that reside within other firms within the firm's network.

3. Resource development perspective. The ability to exploit knowledge/resources acquired through the alliance by using it to determine what resources/capabilities the firm should invest in developing in the future.

In summary, the total benefits that can be generated through an alliance are the sum of common benefits plus private benefits. The division of those total benefits between the alliance partners depends not only on resource dependency theory, but also the theoretical contributions of the related resources perspective, structural holes perspective, and the resource development perspective (see Figure 1). We examine each of these theories in greater detail and apply them directly to the distribution of relational rents in alliances. 
Distribution of Relational Rents

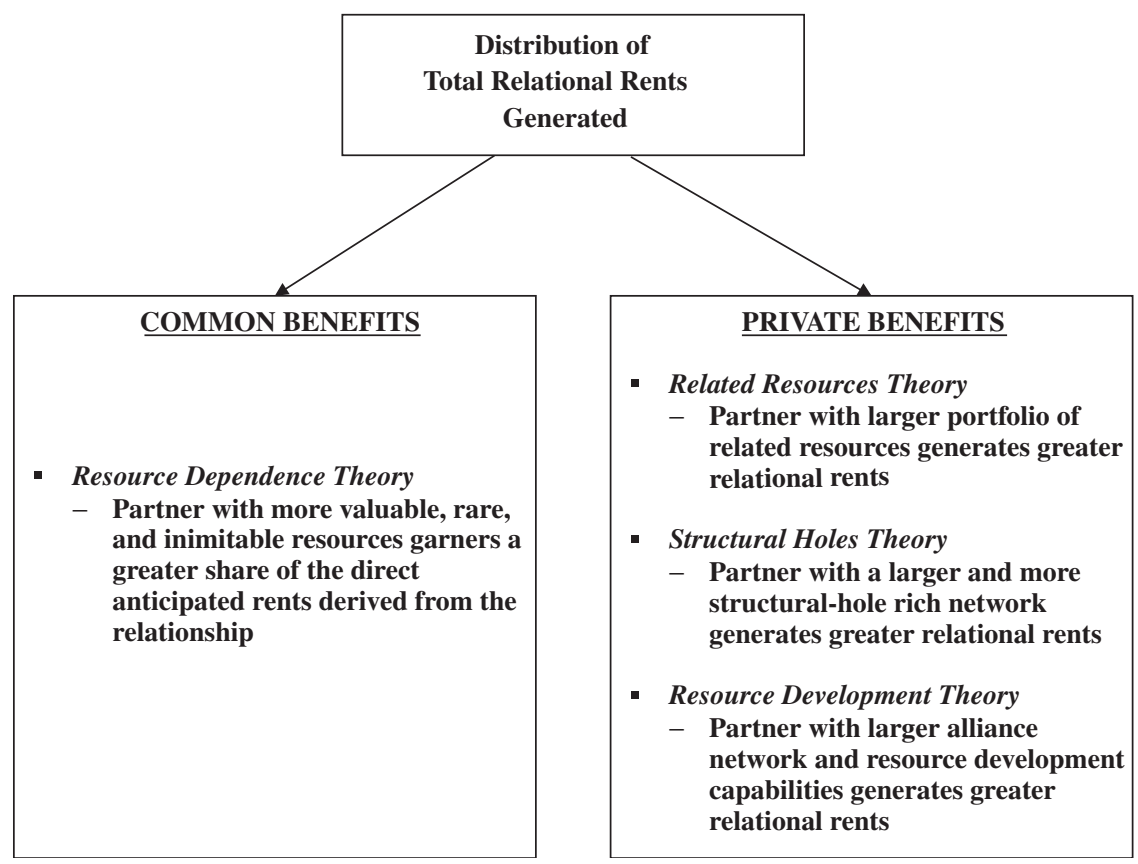

Figure 1. Distribution of relational rents.

\section{SPLITTING COMMON BENEFITS FROM AN ALLIANCE RELATIONSHIP}

\section{Resource Dependence Perspective}

The first perspective, which has already been well developed in the literature, is the resource dependence perspective (Pfeffer and Salancik, 1978). According to the resource dependence perspective, partners who bring the more critical or scarce resources to the relationship (in Barney's 1991 VRIO framework, these would be resources that are valuable, rare, inimitable, and non-substitutable) will have more bargaining power and be able to appropriate a higher percentage of the rents in ex ante negotiations (see Pfeffer and Salancik, 1978; Asanuma, 1989; Barney, 1991). However, as Coff (1999) has shown in his study of bargaining power between knowledge-based employees and firms, this assumes that both parties have a shared understanding with regard to the extent to which each partner possesses resources that are valuable, rare, and non-substitutable (VRIO resources) and the extent to which those resources contribute to the creation of a pie. In short, each partner will determine the extent to which the partner can easily be replaced and how replacing a partner will influence the size of the common benefits created as well as the distribution of those benefits. Thus, a key success factor in appropriating value in an alliance relationship is convincing your partner that you possess VRIO resources and that the partner's share of the pie created (common benefits) will be greater than with any other partner.

Research in the automotive industry provides a nice illustration of resource dependence theory and how it influences the distribution of relational rents. During the 1980-1997 time period, Toyota and its partner suppliers (a 'partner' supplier is defined as one of roughly 20 key suppliers in which Toyota maintains a minority equity stake) made roughly $50 \%$ higher profits than did competing automakers and their suppliers (Dyer, 1996, 2000). Dyer argues that these relational rents are largely generated by relationship-specific investments made by Toyota and its suppliers. For example, Toyota and its suppliers had one-third the inventory to sales ratio as GM, Ford, and Chrysler in large part due to supplier investments in dedicated plants located close to Toyota's plants, which lowered inventory and transportation costs. These investments contributed to the higher joint profits (relational rents) enjoyed by 
both Toyota and its suppliers. However, Toyota made much higher profits $(\mathrm{ROA}=13.0 \%)$ than its partner suppliers (average $\mathrm{ROA}=7.1 \%$ ) which indicates that it was able to appropriate a greater percentage of the gains to collaboration. A primary reason that Toyota was able to appropriate a higher percentage of the gains was due to their greater bargaining power (relative to suppliers) and control over more valuable, rare, and inimitable resources (brand equity, system integration skills, manufacturing know-how, etc.). Suppliers could not easily replace Toyota whereas Toyota could more easily replace a given supplier. However, some partner suppliers like Denso made profit returns $(\mathrm{ROA}=12.8 \%)$ similar to those of Toyota. Why? Because Denso, a supplier of key electronic components, valve timing control systems, heating and air conditioning systems, and instrument panels, brought more valuable, rare, and inimitable resources to the relationship than did other supplier partners. Denso designs and manufactures some of the more complex automotive components that can only be supplied by a few suppliers (fewer substitutes). In fact, a large percentage of Denso's component blueprints during that time period were 'blackbox' blueprints, meaning Denso would blacken out a box on the component blueprint to keep the blueprint proprietary, even from Toyota (see Clark and Fujimoto, 1991; Dyer and Ouchi, 1993). As noted by Clark and Fujimoto (1991, p. 142) 'The black box system is not without its downside risks. Assemblers dependent on suppliers' engineering capabilities may lose some negotiation power.' As a result of possessing proprietary blueprints and capabilities that allowed for delivery of lowcost, high-quality components, Denso was able to appropriate a greater percentage of the gains of collaborating with Toyota relative to the typical partner supplier. In contrast, Chuo Spring a Toyota partner supplier of valve springs, control cables, and leaf springs, made an ROA of roughly $7.5 \%$ during the same time period. Chuo Spring provided parts to Toyota that typically did not involve 'black box' blueprints and were not nearly as complex to design and manufacture as Denso's parts. Moreover, there were roughly twice as many suppliers in Japan who produced Chuo's major products compared to the number of other suppliers who produced Denso's major products. As a result, Chuo was less able than Denso to appropriate the gains from its partnership relationship with Toyota because its resources were less valuable, rare, and inimitable.

\section{Proposition 1a:}

A firm in an alliance/network which brings the more critical (i.e., valuable, rare, inimitable) resources to the relationship will appropriate a higher percentage of the total relational rents generated from an alliance relationship.

While resource dependence will determine the split of common benefits at the time the alliance is initiated (ex ante bargaining power), the bargaining power of partners can change over time (ex post bargaining power). There are two main factors which will influence bargaining power over time: (1) the extent to which the partner learns/acquires the VRIO resources of the partner (thereby changing the relative value of the partner's VRIO resources), and (2) the extent to which the partners make asymmetric investments in relation-specific assets.

In the first case, ex post bargaining power changes as a result of one partner doing a significantly better job of acquiring the partner's knowledge and resources. Naturally, this changes the perception of the relative contributions of the partners to the relationship. Hamel's (1991) detailed examination of nine alliances revealed that the partners typically try to internalize the partner's skills while protecting their own. He found cases where the alliance dissolved because one partner had completely mastered the skills of the other through significant investments in learning. As one manager in his study observed, '[Our partner] tries to suck us dry of technology ideas they can use in their own products.' Thus, from a dynamic perspective, when one firm does a significantly better job of assimilating or replicating the knowledge and resources of its partner, this will change the balance of bargaining power and the distribution of relational rents over time in favor of that firm.

\section{Proposition 1b:}

A firm in an alliance which has made greater investments in acquiring or replicating the knowledge and resources of its partner will increase its bargaining power and appropriate a higher percentage of the subsequent relational rents generated from an alliance relationship.

Manage. Decis. Econ. 29: 137-148 (2008)

DOI: $10.1002 / \mathrm{mde}$ 
A second factor that will influence the distribution of common benefits over time in an alliance relationship is the degree to which alliance partners make asymmetrical investments in transaction-specific assets. As described by Klein et al. (1978), transaction specific investments are valuable because they create appropriable quasi-rents, or value above and beyond what could have been generated through general purpose investments. However, as indicated by transaction cost theory (Williamson, 1985), transaction-specific investments also create the potential for opportunism on the part of the transaction partner who has not made the investment. When alliance partners make symmetric investments in transaction-specific investments, this creates mutual lock-in and these investments serve as credible commitments on the part of both parties. But when transaction-specific investments by alliance partners are asymmetric, the firm that makes fewer investments in transaction-specific assets will have greater bargaining power (greater ability to appropriate the quasirents) in future negotiations regarding the split of the rents generated from those assets. This greater bargaining power derives from the fact that the alliance partner has invested in assets that are not easily re-deployable to other uses.

\section{Proposition 1c:}

A firm in an alliance which has made fewer investments in transaction-specific assets relative to its partner, will increase its bargaining power and appropriate a higher percentage of the subsequent relational rents generated from an alliance relationship.

\section{GENERATING/APPROPRIATING PRIVATE BENEFITS FROM AN ALLIANCE RELATIONSHIP}

\section{Related Resources Perspective}

We would also expect a firm to benefit differentially from an alliance relationship depending on the 'relatedness' of the firm's other activities and resources. Alliances generate 'common benefits' (gains) or benefits to both parties based upon the alliance's specific objectives as well as 'private benefits' or gains that are realized only by individual firms in the alliance (Khanna et al., 1998). To illustrate, private benefits are realized

Copyright (C) 2008 John Wiley \& Sons, Ltd. when a firm has other related resources and is able to take resources or knowledge generated through an alliance and transfer it to other business units/ divisions within the firm not directly related to the alliance. Private benefits are those that a firm can earn unilaterally by acquiring knowledge or resources from its partner and applying them elsewhere. Naturally, for a firm to generate private benefits from the knowledge it has acquired from a partner it must have other 'related' resources within the firm. A company possesses resources that are strategically related to the knowledge or resources acquired from the alliance partner when there is a commonality in one of the following areas: customers (common customers with similar demographics); channels; inputs and suppliers; processes (similar product development, manufacturing or service processes); and technological knowledge base (similar intellectual property, technological know-how, market knowledge) (see Markides and Williamson, 1996). This definition is akin to the earlier and less extensive definition by Rumelt (1974) in his early study of corporate diversification. The work of Koh and Venkatraman (1991) explores the notion of relatedness further in the context of alliances and argues for higher benefits in related alliances.

Another way to operationalize relatedness is to observe the frequency with which assets tend to be combined in corporate portfolios under the assumption that such resource combinations are a source of economic rent. The merit of this approach is that it does not require the researcher to assign categories of relatedness, but instead base it upon revealed relatedness patterns throughout the economy on any given pair of industrial activities. Bryce and Winter (2004) have taken this approach to create a general relatedness index that allows them to determine the relatedness between pairs of industrial activities (or SICs) within a firm's portfolio. This promising line of research would allow one to measure the degree of relatedness between any two SIC codes in which a company conducts business, including the relatedness of a firm's portfolio of businesses and the specific business being conducted within an alliance (Bryce, 2003).

In addition to the greater potential private benefit in a related resource combination, the firms involved would need to have a degree of absorptive capacity to actually realize the benefit. Thus, the successful acquisition of private benefits 
from an alliance is more likely to occur when: (1) the firm's scope of resources and activities is more 'related' to the alliance's activities (the firm has more related resources), and (2) the firm has developed absorptive capacity and effective intraorganizational routines to facilitate intra-firm knowledge and resource transfers. In addition to resource relatedness, absorptive capacity, or a firm's ability to assimilate and utilize new external knowledge (Cohen and Levinthal, 1990) is necessary for a firm to absorb and utilize the knowledge it acquires from an alliance. In some cases a firm may devote significant resources to acquiring knowledge and resources from an alliance relationship while its partner devotes few resources. Hamel (1991) describes a number of cases where Japanese firms acquired significantly greater knowledge and benefits from its alliance relationships with US firms because they devoted significantly greater resources to acquiring knowledge. This suggests that the relative absorptive capacity of alliance partners will influence their ability to generate private benefits from an alliance relationship (see Lane and Lubatkin, 1998 for a discussion of relative absorptive capacity).

To illustrate how related resources can affect the distribution of gains in an alliance, we examine the alliance between Apple Computer Inc. and Sony Corporation to manufacture Apple's successful PowerBook line of portable computers. Before the Apple-Sony alliance, Apple's initial foray into portables was the 'Macintosh Portable' which was 'overpriced' and 'overweight' and frequently described as a 'failure' (BusinessWeek, October 28, 1991; p. 132). The Apple-Sony alliance linked Apple's capability at designing easy-to-use computer products with Sony's miniaturization capability, including the manufacturing know-how necessary to make compact products. An article in Fortune described the alliance as follows:

Apple Computer Inc. enlisted Sony Corp., the Japanese consumer electronics firm, to design a new notebook-size Macintosh computer called the PowerBook. Sony's engineers, who had little experience building personal computers, developed the machine in less than 13 months. Apple approached Sony in late 1989 because it did not have enough engineers to handle a flood of new products planned for delivery in 1991. From the beginning, the idea had the imprimatur of Sony's president, Norio Ohga, who assigned it top priority and watched over it personally. Sony's engineers are currently planning future members of the PowerBook family (Fortune, November 4, 1991, p. 151).

Thus, Apple got Sony's expertise in miniaturization, while Sony learned more about the personal computer (and specifically, the laptop) business (InformationWeek, October 28, 1991, p. 63).

Although both Apple and Sony benefited from the success of the PowerBook, it appears that Sony ultimately realized greater total benefits (the sum of common and private benefits) from the alliance due to greater related resources. In addition to the value generated from the PowerBook, Sony realized greater private benefits due to synergies between its consumer electronics business and its growing computer business (e.g., computer monitors, speakers, and now personal computers and laptops). Sony used the alliance as an opportunity to learn how to design and manufacture laptop computers. It also learned how to manage product development cycles that are much faster in the computer industry than in consumer electronics (Inkpen and Dinur, 1998). Before the Apple alliance, Sony had little direct experience in designing and manufacturing computers. Sony has drawn on its experience with Apple to launch its own independent entry into the personal computer industry, including its popular line of laptop computers. Sony's stated strategy is to be the preeminent brand in the living room as the worlds of computers, communications, and consumer electronics converge (BusinessWeek, May, 17, 1996, p. 100). By comparison, Apple did not build new capabilities through the Sony alliance outside of the computer business, nor did it have related resources that became more valuable as a result of the alliance. Most of the benefits it derived came solely from the PowerBook (of course, these were common benefits which were substantial). However, due to its related resources in consumer electronics and computers, Sony was able to realize much greater private benefits from the alliance than Apple.

The theoretical arguments above have found some empirical support in a study of joint ventures conducted by Koh and Venkatraman (1991) who examined the stock market response to joint venture announcements. In particular, they found that parent firms with businesses related to the joint venture (defined as similar products, markets, 
production technologies, or science-based research) realized abnormal stock market gains that were 10 times higher than for parents without related business units. They conclude that 'The parent with the greatest number of businesses related to a joint venture's business derives more benefits from the venture than the other parent or parents' (p. 885).

\section{Proposition 2:}

A firm whose scope of resources/activities is more related to the alliance/network activities (and which has a high level of absorptive capacity and effective intra-organizational knowledgetransfer routines) will appropriate a higher percentage of the total rents generated from an alliance relationship.

\section{STRUCTURAL HOLES PERSPECTIVE}

Burt (1992) has offered a detailed description of the structural holes perspective. Burt argues that the rate of return that a firm earns is closely linked to the social structure of its competitive arena. Each player/firm has a network of contacts (e.g., customers, suppliers, competitors, etc.) in the competitive arena and the structure of the player's network and the location of the player and its network contacts influence the rate of return or profits that the player can earn. Companies embedded in networks potentially enjoy two kinds of benefits: informational benefits and control benefits.

Information benefits of a network define who knows what about potential business opportunities that might exist among network members, when they know, and who gets to participate in them. Companies with a network optimally structured to provide these benefits enjoy higher returns because such players know about, and can participate in, more rewarding business opportunities. In addition, companies in a network can derive control advantages by being (tertius gardens) or one who is situated between two other actors. Firms in the tertius role can create advantages for themselves by brokering relationships between other players who are not directly connected to each other.

Structural holes refer to the separation or gaps that exist between a firm's non-redundant contacts in a network. Thus, structural holes represent entrepreneurial opportunities for information/ resource access and control. A network rich in non-redundant contacts is rich in structural holes. According to Burt (1992), companies that are located in networks rich in structural holes and that occupy positions that are central or structurally autonomous in that network should enjoy higher returns. The information and control benefits that exist in a network emerge from the wellsprings of structural holes in the network.

Following Burt (1992), we argue that two firms in an alliance relationship who each possess a different network of alliances will benefit differentially from that relationship depending on their position (e.g., centrality) within a network of alliances or relationships. A firm that holds a central or structurally autonomous position in a network that is rich in structural holes will be better able to exploit resource and information differentials obtained through the alliance relationship within the network. Thus, such a firm will realize greater benefits from participating in the alliance than a partner who does not possess a large network of alliances and who does not occupy a central position within that network.

This point is well illustrated by the Tata Group, India's largest business group with a presence in a number of different industries such as steel, automobiles, hotels, information technology (IT), etc. Indian companies, both large and small, possess strong capabilities in the IT field, especially in the area of software development. Indeed, Tata's IT consultancy company recently went public and achieved a market value of roughly $\$ 10$ billion, the largest IPO in India's history. However, to realize the full value of those capabilities, Indian firms like Tata must often link up with foreign firms who can provide business opportunities in more lucrative foreign markets. Many of the smaller Indian companies find it difficult to establish direct relationships with large foreign companies wishing to do business with Indian firms. Instead, these large foreign firms are more likely to work directly with large and visible Indian firms, such as the Tata Group's IT company which acts as an important conduit for enabling business between large foreign firms and smaller Indian firms. The Tata Group has India's largest IT company with dozens of alliances with foreign firms as well as with small domestic firms with strong capabilities who find it difficult to establish direct relationships with large foreign firms. By virtue of its size and its long-term 
presence in this arena, the Tata Group IT company occupies a central position in a network of IT companies that is rich in structural holes, internationally, but more so domestically.

A central position in a network of both domestic and foreign IT firms rich in structural holes enables the Tata Group IT company to appropriate a higher percentage of the gains generated from its partnerships with the smaller Indian firms. Through its alliances with foreign firms, the Tata Group IT company enjoys better and privileged access to information about new business opportunities in the international market, product specifications and pricing, new developments in relevant technologies, etc. Its central position also allow it to retain control over this privileged information as well as relationships. The information and control benefits enjoyed by the Tata Group IT company allows it to negotiate advantageous terms with its smaller Indian partners when they work together to service the needs of large foreign customers. This translates into superior returns for the Tata Group from its alliances, as compared to its smaller domestic partners.

\section{Proposition 3:}

A firm(s) in an alliance/network that occupies a position in the network that is rich in structural holes and, therefore, can exploit resource and information differentials will appropriate a higher percentage of the rents generated from an alliance relationship.

\section{RESOURCE DEVELOPMENT PERSPECTIVE}

The advantage of a firm's information-rich position in a network of alliances may go beyond its ability to profitably broker information/resources (structural holes perspective) and derive associated private benefits. A firm's membership and position in an alliance network may also provide the breadth of information necessary to enable the firm to make important choices regarding the types of resources it chooses to invest in developing for the future.

A firm that has developed a large number of alliance relationships through which it can obtain valuable knowledge will be able to obtain timely and reliable non-public information from its network of relationships. Consequently, the firm can put together a unique picture about relevant future market trends, opportunities and directions and, more importantly, make critical decisions about the types of resources the firm needs to invest in and develop in order to pursue these opportunities successfully. Of course, this depends in part on a firm's 'sense-making' capabilities, which refers to the firm's ability to understand, organize, and make sense of the incoming knowledge, thereby allowing the firm to accurately forecast future economic conditions (e.g., future customer needs, emerging technologies, high growth geographic regions, etc; see Teece, 1998). However, assuming that firms have equal 'sense-making' ability, firms with greater amounts of non-public information and/or information that is more accurate should be in a better position to make investments in resources and capabilities that will pay off in the future. The resources and capabilities that a firm chooses to develop as a result of the knowledge it acquires from its network of alliance relationships will generate benefits for the firm that are indirectly related to any particular alliance. Thus, these are private benefits that a firm with a greater number of alliance relationships will be able to enjoy which will not be available to an alliance partner with a small number of alliance relationships.

To summarize, a firm in an alliance network with superior access to market information through its network of alliance relationships (centrality and breadth of ties) is likely to realize greater private benefits from participating in a network of alliances. Prior research has already shown that firms that occupy central network positions with greater network ties are more likely to increase their number of alliances in the next time period (Gulati, 1995; Koput et al., 1997; Singh and Mitchell, 2005). But as we described above, the benefit also stems not only from having a great number of alliance relationships in the future, but also more importantly, proportionately increasing a firm's ability to tap into a growing number of non-public information sources that each new tie provides, thereby allowing the firm to identify relevant opportunities to deploy as of yet undeveloped resources/capabilities that might be valuable, rare, and difficult to imitate in the future. Thus, we extend the primary argument of prior research on this topic in an important way.

Extant strategy research has also underscored how a firm needs to achieve a fine balance between exploiting the current capabilities it possesses, and 
exploring the development of new capabilities that it might need in future. The various rent generation and distribution perspectives proposed in this paper address this same issue, albeit in the context of a firms' alliance network. The first three perspectives, namely the resource dependence perspective, structural holes perspective, and related resources perspective, essentially highlight the private 'exploitation' opportunities that a firm's alliance network presents the focal firm. In contrast, the resource development perspective underscores the private 'exploration' benefits a firm potentially derives from its alliance network and its central position in that network.

Microsoft is an example of a firm that has dozens of alliances with technology firms and who, as a result of its size and resources (e.g., operating software, cash, etc.), occupies a central position in the alliance landscape in the computing industry. According to Doz and Hamel (1998, p. 233) 'Microsoft has been able to enroll nearly the entire information technology industry in its alliance network.' (This fact is reflected in a Fortune article which argues 'These Days, Everybody Needs a Microsoft Strategy'; Fortune, 1998, p. 134.) For example, Microsoft has more than 40 alliances with Hewlett-Packard alone and is such an important alliance partner that Hewlett-Packard has assigned a full time executive to oversee its alliances with Microsoft. Of course, this represents just the tip of the iceberg as far as Microsoft's total number of alliances is concerned. Without consciously trying, Microsoft uses its numerous alliances to gather information on the market to assist it with internal resource development. Indeed, Microsoft's decisions to enter both the Internet Service Provider (ISP) business with MSN to compete with AOL, as well as its decision to enter the video game box industry with X-Box to compete with Sony were arrived at in part through information acquired through its alliance network (this observation was made by a Microsoft executive during an interview in August, 2004). Its central position in its alliance networks gives Microsoft access to more, and better, information. Microsoft often uses these relationships to gather information on where to invest in the future. In fact, in interviews we have conducted with Microsoft's alliance partners, some partner executives have suggested that Microsoft is not a particularly desirable alliance partner in terms of generating common benefits in an alliance. Microsoft is often described as hard to work with and in some cases the partner indicated that Microsoft has used the knowledge acquired through the alliance to develop new, and perhaps competing, products or services. Thus, Microsoft is able to use its central and information-rich position in its network of alliances to acquire information to help channel its enormous software development and financial resources toward appropriate internal resource/ capability development.

\section{Proposition 4:}

Firms that occupy an information rich position in the network of alliances will be able to appropriate a higher percentage of the gains generated from any individual alliance relationship due to more opportunities (due to more private information) to determine which resources to develop in the future.

\section{BALANCING COMMON AND PRIVATE BENEFITS FROM ALLIANCES}

In the discussion thus far, we have examined common and private benefits in a separate manner and have proposed different theoretical perspectives that best explain the generation of each relevant benefit. But since most firms are likely to earn a certain degree of both private and common benefits in any alliance, we can conceptualize different partnering scenarios based on different possible permutations of common and private benefits. That is to say, common benefits could be high or low, and private benefits could be high or low for each focal firm in the alliance creating four possible scenarios. In the various possible scenarios, there are implications in some instances for alliance longevity and performance. We address each scenario sequentially (Figure 2).

The diagonal elements - high common and private benefits, and low common and private benefits - are relatively straightforward. In the case of low common benefits and low private benefits, the alliance would still be generating some gains for each party, albeit small. Such instances are unlikely to be stable in the long run because of the relatively small payoffs in the alliance. Thus, these alliances are characterized by low-intermediate stability.

The case of high common benefits and high private benefits is the most desirable for all parties in an alliance. Such situations are likely to be 


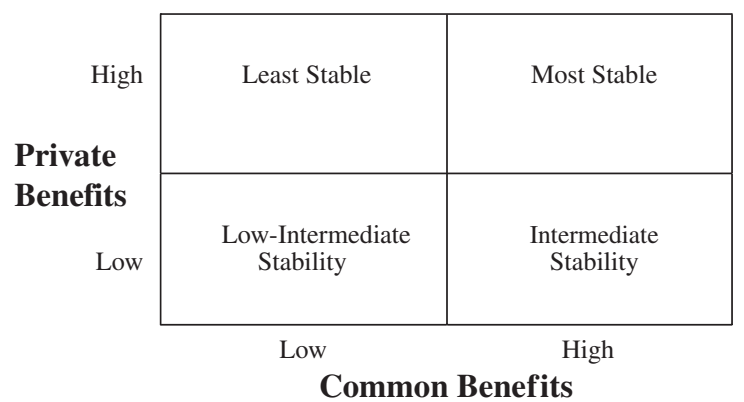

Figure 2. Private and common benefits and alliance stability (Proposition 5).

stable and relatively free of tension between partners, since they are achieving positive and substantial gains from the relationship. As a qualifier to this situation, it is worth noting that partner scarcity could come into play as a constraint - such situations involve high degrees of resource dependence, lower specific investments, and high complementarity, which would apply to only a select few of a full set of possible alliances.

In the case of low common benefit but high private benefit for one partner, there are challenges in terms of the asymmetry of benefit in the alliance. While rationally speaking the relevant basis of decision-making is the alliance versus the focal firm's alternative (not the partner's payoff), it is still possible that tensions would enter the relationship due to the observed asymmetry and perceived lack of equity (Arino and de la Torre, 1998). Such alliances would be the least stable of the possible combinations.

The case of high common benefits but low private benefit for one partner, presents an interesting challenge. In such instances, a purely rational assessment of the payoffs to each partner would reveal a positive situation even for the partner receiving a lower fraction of the total payoff in the relationship, in that the absolute magnitude of payoff to all partners will be high (and presumably higher than their next best investment alternative). However, in instances where alliance performance measurement systems are underdeveloped, it is possible that alliance partners with a lower private benefit and high common benefit would be dissatisfied with their payoff structure. On average, though, instances of high common benefits and low private benefits would result in lower stability than that observed in the case of high common and private benefits, but higher than the other possible combinations of common and private.

These arguments lead to the following proposition:

\section{Proposition 5:}

Contexts of high common and high private benefits would yield the most stable alliances, while contexts of low common and high private benefits would yield the least stable alliances. Situations of low common and low private benefits and high common and low private benefits would have intermediate levels of stability.

In the preceding discussion we have focused more on alliance stability than rent appropriation. We believe that alliance stability plays a role in appropriation of rents particularly in conditions where the alliance is unstable, because the time frame for appropriating the benefits may be longer than the actual duration of the alliance. The high common benefit/low private benefit context is one in which it is feasible that the rents from the alliance may not accrue to the partners concerned, due to the instability of the relationship. However, two additional factors need to be considered. First, what are the expectations of rent distribution and how accurate are these estimates, and second, to what extent can decision makers accurately assess the likely rent distribution to the partner. In instances where the estimates are reasonably accurate, it is possible that the high common benefit/low private benefit relationship could be reasonably stable. Possible examples of this are alliances between relatively small companies and Wal-Mart for distribution of their products. ${ }^{2}$ Although Wal-Mart through its strong bargaining power derived from scale and scope (related resources), networks (structural holes), and resource development (alliance network) may earn a larger proportion of rents, the common benefits are high and the partner may be content with low private benefits from the specific transaction.

\section{CONCLUSION}

Alliances are becoming increasingly important as vehicles for improving economic performance and creating competitive advantages. However, if firms are to get the most out of alliances, they must 
understand the factors that influence their ability to appropriate the greatest gains from participating in alliances and networks. Our paper examines four key ways that firms can appropriate more of the gains through participating in alliances and networks. More specifically, we argue that firms will realize greater gains through participating in alliances when they: (1) bring more critical and scarce resources to the alliance; (2) have more resources that are 'synergy sensitive' with the common benefits realized through the alliance; (3) occupy information-rich positions in an alliance network with numerous structural holes; and/or (4) use an information-rich position in a network of alliances to acquire information to assist in the development of internal resources or future alliances.

In this article we contribute to the literature on alliances by specifically delineating the factors that drive differential payoffs from such relationships. An additional contribution of this paper is that it brings multiple perspectives to bear upon the question of the determinants of alliance payoffs. Our arguments incorporate resource dependencebased considerations as well as considerations that are drawn from the dynamic capability perspective, a transaction cost perspective and from a structural view of the network the firm participates in. This integrative approach is necessary because each of these perspectives is limited in the scope of considerations they identify as drivers of relative gains from alliances.

We anticipate that future research will examine a more dynamic perspective on the processes by which partners in an alliance or network increase their common and private benefits from such relationships. Since many of the factors presented in this discussion (such as asset specificity and the presence of related resources) change over time and also influence the nature of common and private benefits, the incentives for partners to invest in the relationship also change over time. As a result, it is possible to envision scenarios in which some alliances generate substantial value over time in a positively reinforcing cycle, and others in which the promise of the total gains from an alliance is cut short by tensions arising from perceived or real differences in proportion of payoffs. Future research could also examine the role of managerial cognition in these alliance investment decisions: whether decision makers are aware of changes in their network position over time, and whether they determine their investment decisions using strictly rational considerations involving financial and strategic payoffs.

In conclusion, while relational rents have received substantial attention over the past few years, the same cannot be said for the question of the distribution of such rents. In this paper, we address this situation by positing factors that influence the distribution of relational rents, and some of their consequences for stability of alliances. More empirical work is needed to develop the empirical foundations of the propositions we offer in this paper, and to explore the longitudinal impact of these payoffs on the evolution of alliances and networks.

\section{NOTES}

1. Following Dyer and Singh (1998), we use the term relational rent although technically speaking trading partners generate quasi-rents. Peteraf (1994, p. 155) defines quasi-rents as 'returns that exceed a factor's short run opportunity cost. . quasi rents are an excess over the returns to a factor in its next best use.' The term 'quasi-rents' suggests that the rents are not permanent in nature.

2. We thank our reviewer for this insight and example.

\section{REFERENCES}

Anand B, Khanna T. 2000. Do firms learn to create value? Strategic Management Journal 21: 295-316.

Arino A, de la Torre J. 1998. Learning from failure: towards and evolutionary model of collaborative ventures. Organization Science 9: 306-326.

Asanuma B. 1989. Manufacturer-supplier relationships in Japan and the concept of relation-specific skill. Journal of the Japanese and International Economies 3: 1-30.

Barney JB. 1991. Firm resources and sustained competitive advantage. Journal of Management 17: 99-120.

Bryce DJ. 2003. Firm knowledge, stepping stones, and the evolution of capabilities. Unpublished Doctoral Thesis, University of Pennsylvania.

Bryce DJ, Winter SG. 2004. The Bryce-Winter Relatedness Index: a new approach for measuring inter-industry relatedness in strategy research. Working Paper, Marriott School, Brigham Young University.

Burt R. 1992. Structural Holes: The Social Structure of Competition. Harvard University Press: Cambridge, MA.

Business Week 1996. BusinessWeek, May, 17, 1996; 100. Clark KB, Fujimoto T. 1991. Product Development Performance. Harvard Business School Press: Boston, MA. 
Coff R. 1999. When competitive advantage doesn't lead to performance: resource-based theory and stakeholder bargaining power. Organization Science 10: 119-133.

Cohen WM, Levinthal DA. 1990. Absorptive capacity: a new perspective on learning and innovation. Administrative Science Quarterly 35: 128-152.

Doz Y, Hamel G. 1998. Alliance Advantage. Harvard Business School Press: Boston.

Dyer JH. 1996. Specialized supplier networks as a source of competitive advantage: evidence from the auto industry. Strategic Management Journal 17: 271-292.

Dyer JH. 2000. Collaborative Advantage. Oxford University Press: New York.

Dyer JH, Ouchi WG. 1993. Japanese-style partnerships: giving companies a competitive edge. Sloan Management Review 35(1): 51-63.

Dyer JH, Singh H. 1998. The relational view: cooperative strategy and sources of interorganizational competitive advantage. Academy of Management Review 23: 660-679.

Fortune 1991. Fortune, November 4, 1991; 151.

Fortune 1998. Fortune, January 12, 1998. These days, everybody needs a Microsoft Strategy. 134.

Gulati R. 1995. Social structure and alliance formation patterns: a longitudinal analysis. Administrative Science Quarterly 40: 619-652.

Gulati R, Nohria N, Zaheer A. 2000. Strategic networks. Strategic Management Journal 21: 203-215.

Hamel G. 1991. Competition for competence and interpartner learning within international strategic alliances. Strategic Management Journal 12: 83-104.

Information Week 1991. Information Week, October 28, $1991 ; 63$.

Inkpen A, Dinur A. 1998. Knowledge management processes and international joint ventures. Organization Science 9: 454-468.

Kale P, Dyer JH, Singh H. 2002. Alliance capability, stock market response, and long term alliance success: the role of the alliance function. Strategic Management Journal 23: 747-767.

Khanna TR, Gulati R, Nohria N. 1998. The dynamics of learning alliances: competition, cooperation, and relative scope. Strategic Management Journal 19: 193-210.

Klein B, Crawford RG, Alchian AA. 1978. Vertical integration, appropriable rents, and the competitive contracting process. Journal of Law and Economics 21: 297-326.

Koh J, Venkatraman N. 1991. Joint venture formations and stock market reactions: an assessment in the information technology sector. Academy of Management Journal 34: 869-892.

Koput K, Powell WW, Smith-Doerr L. 1997. Interorganizational relations and Elite sponsorship: mobilizing resources in biotechnology. Department of Sociology Working Paper, University of Arizona.

Lane PJ, Lubatkin M. 1998. Relative absorptive capacity and interorganizational learning. Strategic Management Journal 19: 461-477.

Markides CC, Williamson PJ. 1996. Corporate diversification and organizational structure: a resourcebased view. Academy of Management Journal 39: 340-367.

McConnell J, Nantell J. 1985. Common stock returns and corporate combinations: the case of joint ventures. Journal of Finance 40: 519-536.

Peteraf M. 1994. Commentary. Advances in Strategic Management 10B: 153-158.

Pfeffer J, Salancik GR. 1978. The External Control of Organizations: A Resource Dependence Perspective. Harper \& Row: New York.

Rumelt RP. 1974. Strategy, Structure and Economic Performance. Harvard Business School Press: Boston.

Singh K, Mitchell W. 2005. Growth dynamics: The bi-directional relationship between interfirm collaboration and business sales in entrant and incumbent alliances. Strategic Management Journal 26(6): 497-521.

Teece DJ. 1998. Capturing value from knowledge assets: the new economy, markets for knowhow, and intangible assets. California Management Review 40(3): 55-79.

Williamson OE. 1985. The Economic Institutions of Capitalism: Firms, Markets, Relational Contracting. Free Press: New York. 